\title{
Review \\ A Comprehensive Review of Drug Repurposing Strategies against Known Drug Targets of COVID-19
}

\author{
Ankita Khataniar ${ }^{1}$, Upasana Pathak ${ }^{1}\left(\mathbb{D}\right.$, Sanchaita Rajkhowa ${ }^{1, *(1)}$ and Anupam Nath Jha ${ }^{2, *(\mathbb{C})}$ \\ 1 Centre for Biotechnology and Bioinformatics, Dibrugarh University, Dibrugarh 786004, India; \\ ankita.khataniar@gmail.com (A.K.); upathak970@gmail.com (U.P.) \\ 2 Department of Molecular Biology and Biotechnology, Tezpur University, Tezpur 784028, India \\ * Correspondence: s_rajkhowa@dibru.ac.in (S.R.); anjha@tezu.ernet.in (A.N.J.)
}

check for updates

Citation: Khataniar, A.; Pathak, U.; Rajkhowa, S.; Jha, A.N.

A Comprehensive Review of Drug

Repurposing Strategies against

Known Drug Targets of COVID-19. COVID 2022, 2, 148-167. https: / / doi.org/10.3390/covid2020011

Academic Editor: Simone Brogi

Received: 27 December 2021

Accepted: 21 January 2022

Published: 26 January 2022

Publisher's Note: MDPI stays neutral with regard to jurisdictional claims in published maps and institutional affiliations.

Copyright: () 2022 by the authors Licensee MDPI, Basel, Switzerland. This article is an open access article distributed under the terms and conditions of the Creative Commons Attribution (CC BY) license (https:// creativecommons.org/licenses/by/ $4.0 /)$.

\begin{abstract}
Drug repurposing is a more inexpensive and shorter approach than the traditional drug discovery and development process. The concept of identifying a potent molecule from a library of pre-existing molecules or an already approved drug has become a go-to tactic to accelerate the identification of drugs that can prevent COVID-19. This seemingly uncontrollable disease is caused by SARS-CoV-2. It is a novel virus of the Betacoronavirus genus, exhibiting similarities to the previously reported SAR-CoV genome structure and viral pathogenesis. The emergence of SARS-CoV-2 and the rapid outbreak of COVID-19 have resulted in a global pandemic. Researchers are hard-pressed to develop new drugs for total containment of the disease, thus making the cost-effective drug repurposing a much more feasible approach. Therefore, the current review attempts to collate both the experimental and computational drug repurposing strategies that have been utilized against significant drug targets of SARS-CoV-2. Along with the strategies, the available druggable targets shall also be discussed. However, the occurrence of frequent recombination of the viral genome and time-bound primary analysis, resulting in insignificant data, are two major challenges that drug repurposing still faces.
\end{abstract}

Keywords: COVID-19; drug repurposing; repositioning; drug targets; SARS-CoV-2

\section{Introduction}

Drug repurposing is a process to identify new roles for existing drugs and is generally considered an efficient and economical approach [1]. Repurposing-also known as reprofiling, re-tasking, repositioning, and rescue of drugs-can help identify new therapies for diseases, at a lower cost and in a shorter time, particularly in those cases where preclinical safety studies have already been conducted. It can play a crucial role in "therapeutic stratification procedures" for patients with rare, complex, or chronic diseases with few to no treatment procedures. The advent of genetic programming and computational approaches has led to the development of novel strategies for drug-repurposing. It is a convenient alternative when an unexpected medical scenario, such as the coronavirus disease 2019 (COVID-19), which was declared a pandemic by WHO (World Health Organization) in March 2020, presents itself and the need for new drugs becomes inevitable [2,3].

Outbreaks of COVID-19 have presented unique challenges to healthcare professionals. The urgent need to provide appropriate pharmacological therapeutics leaves medical professionals minimal time for new drug discovery. Drug discovery is a daunting task that takes several years, from conception to availability in the market [1]. Since its spread from Wuhan, China, COVID-19 has rapidly claimed the lives of hundreds of thousands of people across the world [1,4]. As of November 2021, 5.2 million people have died so far due to this disease, and confirmed cases of persons with COVID-19 are 262.8 million [5]. The need for vaccines and drugs has become more urgent as new virus variants have evolved much faster than anticipated [6,7]. 
Growing evidence suggests that mutations changing the antigenic phenotype of SARS$\mathrm{CoV}-2$ are in circulation. This requires immediate attention as it affects immune recognition at an alarming degree. SARS-CoV-2 infection uses angiotensin-converting enzyme-2 (ACE2) receptor and transmembrane serine protease (TMPRSS2) to infect human respiratory cells. Mutations that affect the antigenicity of the spike protein of the virus are of significance. The spike protein enables attachment of the virus to the host cell surface receptors like ACE2 and fusion between the virus and cell membranes. It is the principal target of the neutralizing antibodies that are generated after infection [7]. The various mutations of SARS-CoV-2 evolve with time. Thousands of variants have emerged since the pandemic began. The first major variant, termed Variant of Concern (VOC) 202012/01 N501Y and the second major variant 501Y.V2, were detected in the last quarter of 2020 in the UK and South Africa, respectively. Since then, these variants have been detected in over 40 countries. These variants have increased transmissibility, virulence, and low response rates to available diagnostics and therapeutics [8].

To repurpose drugs for the treatment of any disease, one must look into the structure of the causative organism. Coronavirus ( $\mathrm{CoVs}$ ) belong to Coronaviridae, which is a singlestranded enveloped positive RNA virus subdivided into alpha $(\alpha)$, beta $(\beta)$, gamma $(\gamma)$, and delta $(\delta)$. Among them, the $\beta(\beta-\mathrm{CoV})$ group is divided into severe acute respiratory syndrome coronavirus (SARS-CoV); severe acute respiratory syndrome coronavirus-2 (SARS-CoV-2), which is COVID-19; and Middle East respiratory syndrome coronavirus (MERS-CoV) [4]. These viruses are fatal and responsible for respiratory, liver, gastrointestinal, and central nervous system damage in humans and animals. SARS-CoV-2 responsible for COVID-19 is more pathogenic than SARS-CoV and MERS-CoV, and it can transmit from human to human, causing fatal illness. It can lead to severe respiratory problems with several symptoms, including fever, dry cough, vomiting, fatigue, diarrhea, and shortness of breath. The virus SARS-CoV-2 likely binds to epithelial cells in the nasal cavity after inhalation and starts propagating. It migrates down the respiratory tract along the conducting airways, triggering an innate immune response. At this stage, the virus can be detected by nasal swabs. Recent studies suggest that initial viral contact occurs in the nasal mucosa through binding of the viral S (spike) protein to the ACE2 (angiotensin-converting enzyme-2) receptor, followed by cleavage of $S$ protein by TMPRSS2 (transmembrane serine protease 2) [9].

The discovery and licensed use of a drug come with a long gestation period. The development of a drug for any disease, especially for diseases caused by viruses, takes time, even in an accelerated mode; it would take around 3-5 years to market it as a ready-to-use product. The cost of the new drug development process amounts to more than a billion dollars, extending for 10-15 years with a success rate of only 2.01\% [10]. This creates a lag in the productivity of pharmaceutical research to develop a new drug, resulting in a persistent gap between therapeutic needs and available treatments. Despite base evidence being of variable quality, existing drugs have been repurposed in the war against the coronavirus pandemic [11]. Even though vaccines have been made available for the general populace, there is no specific treatment for the patients suffering from the disease. Thus, investigational molecules that fail to show efficacy for a predetermined medication typically provide alternative therapeutic effects for another disease [10]. With computational tools and improving knowledge of virology and clinical presentation of COVID-19, researchers are tapping into a broadening pool of potential pharmacological targets.

Currently, several groups of drugs are being investigated against COVID-19. This includes hydroxychloroquine, remdesivir, chloroquine, lopinavir, ritonavir, and so on. These are established drugs used for the treatment of SARS-CoV, MERS-CoV, and other viruses. As there is an emergency requirement to establish potential inhibitors against COVID-19, repurposing drugs is an ideal strategy to gain headway into the same. During repurposing, virtual screening, pharmacophore modelling, other computational methods, and experimental methods are extensively used. As an example of successful stances in drug repurposing, one need not look any further than the treatment modules for the 
Zika virus, a mosquito-borne flavivirus. Zika virus infection lacks a specific drug or vaccine for its treatment. Over the years, researchers around the globe have screened thousands of previously studied compounds and have identified several compounds with anti-ZIKV activities. Barrows and colleagues identified approximately 24 potential drugs with anti-ZIKV activities from a library of 774 FDA-approved drugs. Based on such studies, niclosamide and azithromycin are the most commonly used drugs in ZIKV treatment, especially for pregnant women. Chloroquine, a commonly used anti-inflammatory and antimalarial drug, is also used to treat the same [10].

The methodologies adopted in drug repurposing can be divided into three broad groups depending on the pharmacological, toxicological, and biological activity information available. These are drug-oriented, target-oriented, and disease/therapy-oriented [10]. This review focuses primarily on the target-oriented methodology of drug repurposing strategies against COVID-19.

\section{Drug Targets of COVID-19}

Human coronaviruses are positive-sense RNA $(30 \mathrm{~kb})$ viruses. Two types of proteins characterize HCoVs, structural (Spike (S), Nucleocapsid (N), Matrix (M), and Envelope (E)) and non-structural proteins (nsp1 up to nsp16), including the RNA-dependent RNA polymerase (RdRp) (nsp12). Approximately two-thirds of the $5^{\prime}$ end of the SARS-CoV-2 genome encodes two overlapping polyproteins: pp1a and pp1ab12. Two viral proteases digest them into 16 non-structural proteins (NSPs) essential for viral replication and transcription. Four ORFs at the $3^{\prime}$ terminus of the viral genome encode a set of structural proteins, including the nucleocapsid $(\mathrm{N})$, spike $(\mathrm{S})$ protein, membrane $(\mathrm{M})$ protein, and envelope $(\mathrm{E})$ protein. These are responsible for virion assembly and participate in the suppression of the host immune response. The $S$ protein is a surface-located trimeric glycoprotein of coronaviruses that promotes the attachment of viruses to the host cells through binding to angiotensin-converting enzyme 2 (ACE2) and virus-cell membrane fusion during viral infection. Thus, the $S$ protein has been considered a significant target for developing vaccines and therapeutics against SARS-CoV-2 [12,13].

\subsection{Spike (S) Protein}

Membrane fusion is a key early step for entering host cells and establishing infection for all enveloped viruses. Although it is an energetically favourable process, membrane fusion has high kinetic barriers when two membranes approach each other, mainly because of repulsive hydration forces [14]. For viral membrane fusion, free energy to overcome these kinetic barriers comes from refolding virus-encoded fusion proteins from a primed, metastable prefusion conformational state to a stable, postfusion state [15]. The fusion protein for $\mathrm{CoV}$ is its spike (S) protein that decorates the virion surface as an extensive crown (hence, "corona"). The protein also induces neutralizing antibody responses and is, therefore, an important target for vaccine development $[16,17]$. In March 2020, the structure, function, and antigenicity of the SARS-CoV-2 spike glycoprotein were reported [18]. The $S$ protein is a glycosylated type I membrane protein anchored in the viral membrane. It is first produced as a precursor. After trimerization, it is thought to be cleaved by a furin-like protease into two fragments: the receptor-binding fragment S1 and the fusion fragment S2. Binding through the receptor-binding domain (RBD) in S1 to a host cell receptor (angiotensin-converting enzyme 2 (ACE2) for both SARS-CoV and SARS-CoV-2) and further proteolytic cleavage at the second site in S2 (the S2' site) by a serine protease, transmembrane serine protease 2 (TMPRSS2), or the endosomal cysteine proteases cathepsins $\mathrm{B}$ and $\mathrm{L}(\mathrm{CatB} / \mathrm{L})$ are believed to trigger dissociation of $\mathrm{S} 1$ and irreversible refolding of S2 into a postfusion conformation, a trimeric hairpin structure formed by heptad repeat 1 (HR1) and heptad repeat 2 (HR2). These large structural rearrangements bring together the viral and cellular membranes, ultimately leading to the fusion of the two bilayers $[17,18]$. 


\subsection{Nucleocapsid (N) Protein}

The nucleocapsid protein is a crucial component that protects the viral RNA genome and packages it into a ribonucleoprotein complex. In addition, it regulates the replication and transcription of viral RNA, and it inhibits protein translation through EF1 $\alpha$-mediated action, alteration of host cell metabolism, host cell cycle ( $\mathrm{N}$ proteins are reported to inhibit $\mathrm{CDK} 4$ ), and apoptosis in the host. The $\mathrm{N}$ protein also plays a role in antagonizing the host immune response and has been identified to counter cellular RNAi-mediated antiviral activities by binding with double-stranded RNA. Thus, it can be regarded as a viral suppressor of RNA silencing. The N protein is potentially a target for vaccine development because it induces severe immune responses during infection [12].

The three characteristic intrinsically disordered regions (IDRs) of the nucleocapsid (N) protein are the N-arm, central linker (CL), and the C-tail. The NTD and the CTD are the major structural and functional domains of the nucleocapsid protein. An essential function of the N protein NTD is RNA binding, while the primary job of the CTD is dimerization. The N-NTD has the shape of a right-handed fist, containing a four-stranded antiparallel $\beta$-sheet as a core subdomain. The loops protruding from the core are positively charged, thus allowing RNA binding. The N-CTD homodimer forms a rectangular shape, with each protomer displaying a crescent shape. To stabilize the dimer interface, two $\beta$-hairpin structures from each protomer can form four antiparallel $\beta$-strands by inserting themselves into each cavity. Compared with other coronaviruses, the N protein from SARS-CoV-2 displays different charge distributions in the $\mathrm{N}$-terminal loop, the RNA protruding tip, the bottom of the N-NTD core, and the N-CTD $\beta$-strand face. Hence, the variations in RNA binding to the $\mathrm{N}$ protein may further guide inhibitor optimization [12].

The crystal structure of the SARS-CoV-2 nucleocapsid N-terminal domain has been solved (PDB code: $6 \mathrm{M} 3 \mathrm{M}$ ), showing an overall similarity with the same domain from other $\mathrm{CoVs}$, although the surface electrostatic potential showed a specific distribution. These critical structural findings will significantly push the drug discovery of ligands focused on blocking coronavirus replication and transcription. The success in developing compounds that interfere with $\mathrm{N}$ proteins of other $\mathrm{CoVs}$, such as the recent discovery of stabilizers of the protein-protein interaction of MERS- $\mathrm{CoV} N$ protein, reinforces the $\mathrm{N}$ protein's potential as a druggable target for SARS-CoV-2 infection. The N protein is highly immunogenic and is considered a potential vaccine target for COVID-19 [19,20].

\subsection{Envelope (E) Protein}

The structure of the SARS-CoV-2 E protein solved by nuclear magnetic resonance spectroscopy shows that it is composed of a five-helix bundle $\sim 35 \AA$ in length [21]. The E protein has been found to be involved in viral assembly and budding by localizing to the endoplasmic reticulum (ER) and Golgi body membranes. Moreover, the E protein has been shown to participate in activating the host inflammasome. After a coronavirus enters host cells, the E protein regulates viral lysis and the subsequent viral genome release.

The E protein is involved in the regulation of pumping $\mathrm{Ca}^{2+}$ out of the endoplasmic reticulum, which activates the cellular inflammasome, thereby enhancing host antiviral response. As the E protein can function as an ion channel, the pore inside the transmembrane region is predominantly occupied by hydrophobic residues except for the $\mathrm{N}$-terminal pore. Due to non-specific interhelical interactions, the entrance site at the $\mathrm{N}$ terminus is a drug target for inhibitor binding [22].

\subsection{Membrane (M) Protein}

Maintenance of the shape of the viral envelope is the most crucial function of the $\mathrm{M}$ protein. M protein achieves this by interacting with other $\mathrm{CoV}$ proteins, incorporating Golgi complex into new virions, and stabilizing nucleocapsid protein [22,23]. The M protein is characterized by three TM domains with C-terminal inside (long) and $\mathrm{N}$-terminal (short) outside. The M protein plays a crucial role in viral intracellular homeostasis through 
multiple protein-protein interactions. Interaction between $\mathrm{M}-\mathrm{M}, \mathrm{M}-\mathrm{S}$, and $\mathrm{M}-\mathrm{N}$ proteins takes a particular part in viral assembly.

The $\mathrm{M}$ protein and the $\mathrm{N}$ protein are the major viral envelope proteins that define the viral shape. The M-S interactions are necessary for the interaction of spike protein in the Golgi complex, which is later incorporated into new viral progenies. The M-N interactions are crucial for stabilizing the RNP complex (nucleocapsid-RNA complex), which forms the viral core. $\mathrm{M}$ protein also takes part in the formation and release of virus-like particles. It is involved in the sensitization of the host by the virus by activating the nuclear factor kappa pathway and IFN-beta pathway through a Toll-like receptor-dependent mechanism [23].

\subsection{Non-Structural Proteins (NSPS)}

The SERS-CoV genome encodes several proteins. The replicase gene, a major component of the CoV genome, is encoded for 16 NSPs in the form of two large PPs (PP1a and PP1ab). Two types of cysteine proteases act on these PPs to release the NSPs. The Cterminal end of these PPs is cleaved by chymotrypsin-like cysteine protease (main protease (Mpro) or 3C-like protease (3CLpro)), and the N-terminal end is processed by the Mpro (also known as papain-like protease (PLpro)). Mpro is a vital drug target due to its essentiality in processing polyproteins to produce several viral structural and non-structural proteins. Previous research has shown that the ACE2 entry receptor, the RNA-dependent RNA polymerase (RdRp), has no human counterpart. Together with its role in the virus's life cycle, this fact makes it an attractive drug target for antiviral development [20].

Coronaviruses are undergoing mutations at an alarming rate. This provides a goal of identifying promising targets for antiviral therapies against SARS-CoV-2 so that researchers can exploit the structural similarities among different coronaviruses and focus on those proteins that are highly conserved across multiple coronaviruses. Among the several potential targets of coronaviruses, replication-related enzymes, such as RdRp and protease, are highly conserved. Hemagglutinin esterase enzyme is present in the envelope of $\mathrm{CoV}$, more specifically among beta-coronaviridiae. The $\mathrm{HE}$ is a marker of $\mathrm{CoV}$ and influenza virus evolution. HE mediates reversible attachment to O-acetylated-sialic acids by acting as lectins and receptor-destroying enzymes. Interactions between $\mathrm{HE}$ in complex with sialic acid can be visualized in PDB ID: 3CL5 [23].

NTPase/helicase plays a vital role in the central dogma of the virus. SARS-CoV helicase enzyme is a member of the SF1. It prefers ATP, dATP, and dCTP as substrates and hydrolyzes all NTPs. Toxicity issues are the main obstacles in developing helicase inhibitors, and nonspecificity of inhibitors may cause severe toxicity. Despite theoretical limitations, helicase is being increasingly recognized as a potential drug target for different disease conditions [24].

\section{Strategies in Drug Repurposing for COVID-19}

For rapidly establishing drugs for arising and re-emerging viruses, drug repurposing is one of the most substantial preferences nowadays. Given the SARS-CoV-2 pandemic, compared to de novo drug development, drug repositioning appears as a favourable perspective to develop efficient therapeutics. Traditional drug repurposing techniques establish drug effects and their mode of action (MoA). This process employs screening techniques of current pharmacopoeia to reveal novel drug indications of already established drugs [25]. Drug repurposing for COVID-19 undergoes three steps before getting considered for development and marketing: candidate drug identification; mechanistic evaluation of the drug effect in preclinical models; and evaluation of candidate drugs' efficacy in phase II clinical trials. Among these three steps, the first step-the screening and identification of drugs with a high potential for repurposing - is the most crucial. As such, drug repositioning has two alternative and complementary approaches: an experiment-based approach and a theoretical or in silico-based approach, as shown in Figure 1 [26-28]. 


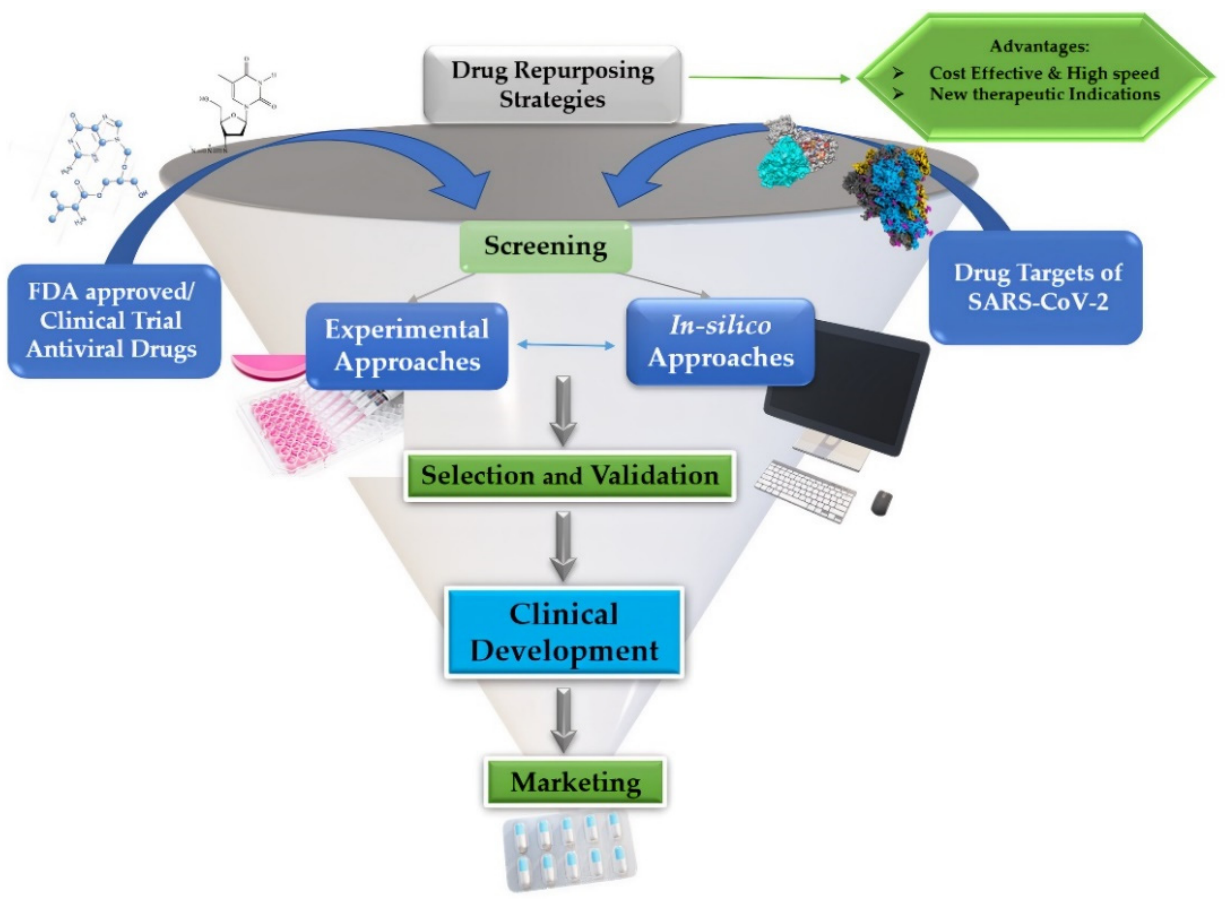

Figure 1. Two alternative and complementary drug repurposing approaches: one is an experimentbased approach, and the other is a theoretical or in silico-based approach.

The experiment-based approach, also known as activity-based repositioning, refers to screening original drugs for new pharmacological applications based on experimental assays. It involves protein-target-based and cell-based screens in disease models without requiring any structural information of target proteins. Approaches of experimental repositioning include the target screening approach, cell assay approach, animal model approach, and clinical approach [29].

In contrast, in silico repositioning involves virtual screening of public databases of huge drug/chemical libraries using computational biology and bioinformatics/cheminformatics tools. In this approach, the identification of potentially bioactive molecules is achieved based upon the molecular interaction between drug molecules and protein targets. Although experimental explorations are functional for drug efficacy determination, they may be time-consuming with small-scale results. Therefore, computational methodologies have enhanced this approach by digging deeper into drug executions, being capable of evaluating the interaction of ligand(s) with respective target proteins, predicting the novel signalling pathways, and making rapid development in lesser time with reduced costs, which is significant for the current pandemic (COVID-19) situation [30].

\subsection{Experimental Approaches}

\subsubsection{Binding Assays to Identify Target Interactions}

Today, analyses of the targets and off-targets of drugs and drug repurposing complement each other. Proteomic techniques such as affinity chromatography and mass spectrometry have been used as approaches to identify binding partners for many drugs. Experimental assays of pre-approved drugs are being adopted in laboratories to bridge the gap between instant diagnosis and long-term research required for the availability of treatment for COVID-19 [31]. The cellular thermostability assay (CETSA) is one such technique introduced to map target engagement in cells using biophysical principles that predict thermal stabilization of target proteins by drug-like ligands that possess the appropriate cellular affinity [32]. Examples of execution of this technique include the confirmation of cellular targets for the tyrosine kinase inhibitor (TKI) crizotinib and the detection of quinone reductase 2 (NQO2) as a cellular off-target of acetaminophen (paracetamol) [33]. In a study 
by Friman et al., a panel of drugs was screened using the CETSA MS format on HepG2 cells to identify host proteins. The experiment was designed to study off-target effects of remdesivir and chloroquine as repurposed drugs for targeting SARS-CoV-2. This leads to a hopeful venture to further improve or develop fortuitous therapies for SARS-CoV-2 infection [34].

The promiscuity of protein kinase inhibitors has increased efforts to develop better compounds for preclinical research that can help clinical drug development and repurposing through evidence-based pharmacological assays. It is also noteworthy that fallacies made in various kinase drug discovery approaches have led to seeking out beneficial pathways of cellular effects through early-stage affinity approaches. Numerous kinases have been considered essential mediators of various viral infections, particularly SARS-CoV and MERS-CoV. These same proteins are also predicted to be involved in mediating infection by SARS-CoV-2 as well. Many kinase inhibitors with pharmacologic effects that may be beneficial in mitigating the severe and potentially life-threatening symptoms of COVID-19 are already approved. Kinase inhibitors can be tested in combination with antiviral agents or other targeted therapies that work against COVID-19 to achieve greater efficacy [35].

Tyrosine-protein kinase (ABL) inhibitors have been demonstrated to inhibit replication of several unrelated viruses like dengue and Ebola in in-vitro cell-based studies. ABL inhibitors, imatinib and dasatinib, were identified as inhibitors of both SARS-CoV and MERS-CoV replication. Nilotinib was identified as an inhibitor of SARS-CoV. Investigation of the mechanism for imatinib against both SARS-CoV and MERS-CoV revealed inhibition of the early stages of the virus life cycle and inhibition of viral replication through blocking the fusion of the coronavirus virion with the endosomal membrane. Importantly, authors show that targeted knockdown of ABL2, but not ABL1, significantly inhibited SARS-CoV and MERS-CoV replication/entry in vitro [35].

JAK inhibitors belong to a family of DMARDs or disease-modifying antirheumatic drugs, which have been repurposed to treat COVID-19. Chen et al. have summarized the observational studies of the clinical uses of Janus Kinase (JAK) inhibitors, including ruxolitinib, baricitinib, and tofacitinib for COVID-19 patients. They compared the clinical efficacy of JAK inhibitors of different meta-analyses and concluded that they are safe agents and can lead to a better clinical outcome for COVID-19 patients [36].

Diving into chemical genetics, one can also better understand the relationship between binding and efficacy in the cellular context. Non-kinase targets of small molecules designed initially to inhibit protein kinases are increasingly recognized. Their validation has led to repurposing opportunities in cancer, as Zika virus modulators and potential agents to treat cancer antibiotic-resistant microorganisms [37]. Small-molecule-kinase binding is analyzed in a kinome-wide fashion using various in vitro and increasingly organism-based assays to generate heat maps of biologically essential interactions. Thus, findings can be rapidly translated into new clinical developments to address drug-resistance outcomes in cancer. Many of these studies stem from industry-driven high-throughput direct binding or catalytic assays [32]. Karaman and colleagues used an in vitro competition binding assay to evaluate 38 kinase inhibitors against a panel of 317 distinct human protein kinases in one such study. Their analysis identified a total of 3175 binding interactions. Interestingly, some kinase inhibitors such as sorafenib and dasatinib showed higher affinity to secondary kinase targets than their known primary target [38]. Such studies show that drug repurposing may indeed be a quick and effective combat strategy against the current pandemic.

\subsubsection{Phenotypic Screening}

Phenotypic screening puts forward drug candidates to proteins in more biologically relevant contexts than screens involving purified proteins. These screens determine cellular function without the requirement of prior knowledge of the relevant targets and signalling pathways, and they offer the possibility of discovering new therapeutic targets [39]. Phenotypic screening can identify compounds that show disease-relevant effects in model systems without prior knowledge of the target(s). In the context of drug repurposing, 
if the compounds screened are approved or investigational drugs, this may fast-track repurposing opportunities that can readily be pursued.

Typically, in vitro phenotypic screens use a wide range of cell-based assays in a 96-well format. For example, Chen et al., in 2021, tested a total of 8810 approved and investigational compounds, out of which 319 compounds were found to have anti-SARS-CoV-2 activities [40]. These included 91 approved drugs and 49 investigational drugs. The antiSARS-CoV-2 activities of 230 of these confirmed drugs had not been previously reported, including 38 approved drugs from the same. The three most potent FDA-approved drugs with anti-SARS-CoV-2 activities were chlorprothixene, methotrimeprazine, and piperacetazine [40].

The compounds that were tested were either mechanism-based bioactive compounds or natural products. They were selected from compound libraries like NCATS Pharmaceutical Collection (NPC), NCATS Mechanism Interrogation Plate (MIPE), NCATS Pharmacologically Active Chemical Toolbox (NPACT), Epigenomic library, Autophagy library, and anti-infective library. A SARS-CoV-2 CPE assay was conducted to check for anti-SARS-CoV-2 activities [41].

The SARS-CoV-2 CPE is a $72 \mathrm{~h}$ assay that measures the phenotypic consequence of viral infection and cell replication [42]. SARS-CoV-2 induces cell death after 48 to $72 \mathrm{~h}$ of infection, and thus cell viability is an indirect measure of viral replication in vitro. Due to its dependence on the host response and its indirect measurement of SARS-CoV-2 infection and replication, the CPE assay may have certain limitations. The phenotypic outcome can also vary depending on culture conditions, the viral multiplicity of infection (MOI), and the number of virions added per cell during infection [43-45].

\subsection{Computational Approach}

For the apprehension of the virus origin and to recognize the evolutionary relationship, other computational procedures are utilizing various computational and AI-based tools. Omics analysis, including proteomics, genomics, metabolomics, epigenomics, and transcriptomics, plays a crucial part, along with classifying the sequence of the virus and its mutational variants, manifesting the sequence and 3D structure of the viral proteins, indispensable for repurposing and discovery of drugs together with the development of vaccines [46,47]. Target-based, network or pathway-based, knowledge-based, signaturebased, and artificial-intelligence-based techniques are the most common computational methodologies, as shown in Figure 2.

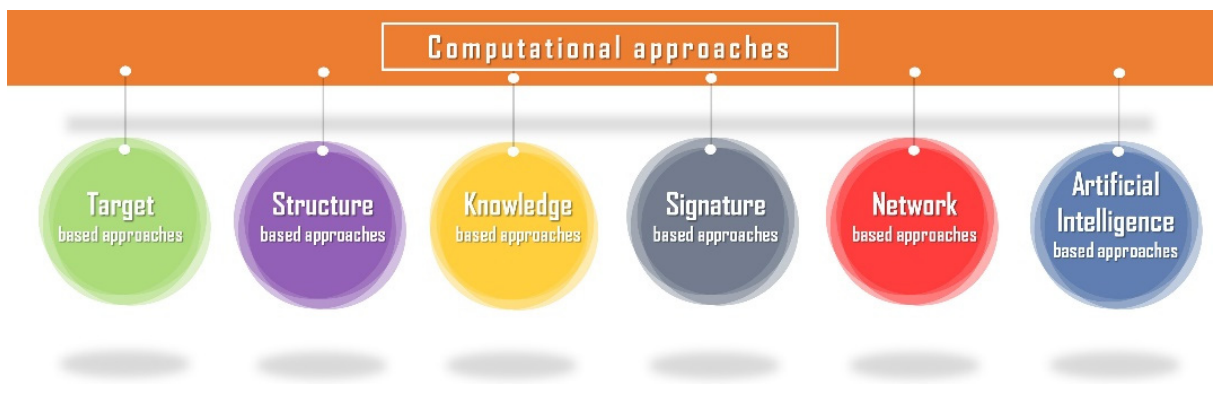

Figure 2. Six major in silico approaches play a major role in identifying drugs with high potential to be repurposed.

\subsubsection{Drug-Focused Strategies}

Polypharmacological techniques focus on how a particular medication affects numerous endpoints in a specific disease pathway or across several disease pathways, and while looking for a novel target for an existing medicine, assessing drug-target binding and interaction might assist in finding additional structurally comparable compounds that have the same target binding capabilities. The polypharmacological strategy also aids in the discovery of undiscovered off-target effects for currently available medications. 


\subsubsection{Target-Based Approaches}

The investigation of substances or stimulants from vast compound libraries as potential drugs for a targeted protein or a biomarker of interest (i.e., protein, receptors) to discern a biochemical reaction is known as target-based screening. Ligand-based inspection or molecular docking $[48,49]$ are examples of target-based methods. When contrasted with unbiased research approaches, such strategies have a better chance of uncovering valuable leads. It also takes a minimal time to complete the entire screening procedure. Novel observations are discovered using this method, which involves connecting a drug to a particular disease predicated on its target proteins. As previously stated, a new indication for a medicine can be defined based on both the principal and off-target molecules. Target repositioning is the process of treating a new indication by associating with the same target molecule as discovered initially. Off-target placement occurs when an authorized medicine engages with a second target and can be used to manage a new indication $[50,51]$.

Computational analysis for drug repurposing of an azamacrocyclic compound, grazoprevir - an antiviral drug first validated for hepatitis $C$ virus and approved by the FDA - which with viral replication targeting RNA-dependent RNA polymerase (RdRP) and transmembrane serine protease 2 (k) (TMPRSS2), along with angiotensin-converting enzyme 2 (ACE-2) proteins produced an optimal binding affinity. Moving further with the procedure of molecular dynamics simulations as well as molecular mechanics PoissonBoltzmann surface area evaluation recognized the drug-receptor interactions and the stable association of grazoprevir with all the proteins, which may be a functional therapeutic for COVID-19 treatment [52].

Another approach using FDA-approved drugs, included 8395 compounds from the DrugBank library. Several natural compounds and various target proteins of SARS-CoV-2namely, the RNA-binding domain of nucleocapsid phosphoprotein, Nsp12 RNA-dependent RNA polymerase, the Nsp3 ADP ribose phosphatase, the Nsp5 3-chymotrypsin-like protease (3CLpro), Nsp14, the Nsp15 endoribonuclease, and the Nsp16 2'-O-MTase were studied using Docking techniques which observed 124 potential inhibitors after screening. This could be a feasible direction for repurposing of these drugs, together with predicting tipranavir as well as nelfinavir, taking $3 \mathrm{Clpro}$ as their target [53].

An efficient computational drug repurposing study of five neutral drugs-valrubicin, elbasvir, lopinavir, eravacycline, and carfilzomib—identified these drugs as possessing inhibitory activities opposed to the SARS-CoV-2 main protease and suggested them as the best drug repurposing candidates. For the SARS-CoV-2 main protease, streptomycin may also be an inhibitor, and some residues for the receptor-ligand-binding contributing to the protein-ligand binding have also been identified, which may enable the design of novel inhibitors targeting the SARS-CoV-2 main protease [54].

\section{Approaches Based on Structure}

Virtual evaluation can aid in the identification of tiny chemicals capable of binding macromolecular targets with known or expected three-dimensional structures. It enables the screening of millions of substances in a short amount of time, lowering the costs of discovering hits for drug discovery and development, as well as discovering new targets for patented drugs. This method is primarily founded on molecular docking [55,56], a computational paradigm that was originally created to comprehend how a pharmacological molecule interacts with a biological equivalent, which is now widely utilized for a variety of activities, including therapeutic repositioning [57-59].

Before crystal structures of viral particles were accessible, the first instance of structurebased medication repurposing performed for COVID-19 were reported. The architectures of numerous target viral proteins were predicted using homology modelling approaches. In most cases, the findings were not experimentally validated. The molecules of compounds in a docking-ready manner were traditionally the beginning point for screening infrequent items, with at most a portion allocated to authorized medications, which may supply the biomolecules of the compounds in a docking-ready style. Additionally, an investigation 
of the structural properties of Mpro discovered significant changes in the structure and size of this protease's active sites compared to the SARS-CoV protease, indicating that repurposing SARS medicines for COVID-19 may be futile. Ribonucleoside inhibitors, antiretrovirals, nucleotide inhibitors, antimalarials, antineoplastics, immunomodulators, steroid hormones, and protease inhibitors account for the majority of the hits identified in these investigations [60]. Scientists who established publicly available web servers to forecast targets and multitarget- and multi-site-based virtual screening added an extra input to the structure-based strategy for drug repurposing.

Employing the docking methodology with molecular dynamics simulation, an exploration for interpretation of the inhibitory system for the nucleocapsid protein in SARS$\mathrm{CoV}-2$ with antiviral molecules together with the stability of protein-ligand complex was established and revealed that saracatinib, nafamostat, rapamycin, trametinib, and camostat were the top hit compounds, suggesting these residues as potential sites of drug targeting for the SARS-CoV-2 N protein that can be utilized for COVID-19 treatment [61,62].

For protein inhibition, approximately 50 antiviral drugs were collected in a research approach, examined utilizing the process of molecular docking for drug target proteins, the spike of SARS-CoV-2, RNA-dependent RNA polymerase (RdRp), and main protease. The drugs lopinavir, indinavir, nelfinavir, remdesivir, and saquinavir showed maximum inhibitory potential as drugs for SARS-CoV-2 inhibition, and lopinavir with saquinavir was highest of all after further laboratory evaluation [63].

Similarly, 15 drugs-quinapril, sofosbuvir, amphotericin B, baloxavir marboxil, fosinopril, danoprevir, clarithromycin, atrovastatin, telmisartan, sulfamethoxazole, virginiamycin, micafungin, tunicamycin, caspofungin, and fidaxomicin - which are FDA-approved, were established as SARS-CoV-2 protein inhibitors in an approach confirmed by docking protocol. They could be explored as drug candidates against COVID-19 in the future and be repurposed against SARS-COV-2 [64].

Likewise, subsequent research of 6218 clinical trials and FDA-approved drugs were virtually screened for RNA-dependent RNA polymerase and main protease as well, resulting in 15 and 23 possible repurposed drugs for treating COVID-19, selecting Mpro as well as RdRp, respectively. The drugs tipifarnib, omipalisib, and emodin exhibit antiSARS-CoV-2 activities in human lung cells, while Calu-3 and drug combinations including tipifarnib/remdesivir, tipifarnib/omipalisib, and omipalisib/remdesivir revealed secure synergistic effects for SARS-CoV-2 inhibition [65].

Another examination for Sar9 Met (O2)11-Substance P along with BV2, which are peptide-based drugs, using the same methodologies of molecular docking then molecular dynamics along with protein-protein interaction simulations, predicted these drugs as inhibitors of the interaction of SARS-CoV-2 spike protein with the human angiotensinconverting enzyme 2 (hACE2) by having a high probability of binding with the SARS-CoV-2 spike protein connecting side on the human angiotensin-converting enzyme 2 (hACE2) receptor, enough for the protein-protein interaction regulation preferred by the virus [66].

Procedure Based on Pathways or Networks

Pathway- or network-based techniques leverage illness omics data, existing signaling or biochemical functions, and interacting protein connections to reassemble disease-specific circuits that serve as major targets for repositioning medicines by which the medicine displays its effectiveness and drug-target relationships. Networks may be used to describe molecular interactions in biological systems, from developments in high-throughput technologies and bioinformatics tools. As a result, a particular network consisting of a few more individual goals may be identified from a broad network of diverse paths. These approaches benefit from being able to pin down broad signaling networks with a huge range of proteins to a specialized network with only some proteins (or target molecules) [50,51,67].

The goal of network-based pharmaceutical research is to use the capacity of systems to shed light on the processes of the effect of current or new compounds so that innovative therapeutic remedies can be identified. Because of their capacity to incorporate diverse 
data sources, network-based techniques are critical and frequently employed in medication repositioning. Nodes in the network represent medications, illnesses, or nucleotide sequences in these models, whereas edges reflect node interactions or linkages. The resultant pattern may make structure-guided pharmacological and medical research possible, with the possibility of discovering novel biological targets. Drug-target networks, drug-drug networks, drug-disease networks, and protein interaction networks have all been shown to be effective in identifying new options for drug development or repositioning in previous research. In the human protein-protein interaction network, the network-based approach combines a system-pharmacology-based network medicine framework that analyzes the interaction between the virus-host interactome and therapeutic targets $[68,69]$.

Recently, by a network-based algorithm, 282 repurposable drugs, like hydroxychloroquine, chloroquine, heparin tocilizumab, and combination therapies of other drugs, including remdesivir, ritonavir, lopinavir, chloroquine, and hydroxychloroquine, were identified. Moreover, based on their network-based similarity values, 24 potential anti-SARS-CoV repurposable drugs were observed. These drugs include thrombin inhibitors, ACE inhibitors, and monoclonal antibodies such as anti-IL6, anti-TNF $\alpha$, anti-IL1 $\beta$, anti-IFN $\gamma$, and anti-IL12 [70].

Another computational antiviral drug repurposing procedure identified 16 potential anti-HCoV repurposable drugs, including melatonin, sirolimus, and mercaptopurine, together with three possible combinations of drugs, namely sirolimus plus dactinomycin, toremifene plus emodin, and mercaptopurine plus melatonin, using a system-pharmacologybased network medicine system, in between the HCoV-host interactome along with target proteins in the human protein-protein interlinkage network. The significant druggability of this $\mathrm{HCoV}$-host interactome facilitates the creation of a drug repurposing approach towards 2019-nCoV/SARS-CoV-2 therapy by precisely addressing protein molecules linked with HCoVs. These network accessibility evaluations identify possible repurposable options for $\mathrm{HCoV}$ treatment and prevention. Furthermore, phylogenetic recognition of $15 \mathrm{HCoV}$ whole genomes to examine the evolutionary connection of 2019-nCoV/SARS-CoV-2 with several other HCoVs revealed that the complete genome of 2019-nCoV/SARS-CoV-2 shows 99.99 percent nucleotide sequence similarity. From the six previous common pathogenic HCoVs [71-73], the 2019-nCoV/SARS-CoV-2 has the greatest nucleotide sequence similarity (79.7 percent) with SARS-CoV, indicating a maintained evolutionary connection with 2019-nCoV/SARS-CoV-2 and SARS-CoV. When compared to SARS-CoV, the envelope as well as nucleocapsid proteins of 2019-nCoV/SARS-CoV-2 are the evolutionarily conserved areas, with 96 percent and 89.6 percent sequence identity, respectively [74].

\section{Knowledge-Based Methods}

Blinded (unintentional, serendipitous findings) and target-based techniques, while successful, cannot be used to investigate novel drug-target relationships. Knowledge-based strategies integrate existing data about a medicine to predict heretofore unrecognized procedures, namely the availability of unrecognized drug targets for older pharmaceuticals, unknown drug-drug correlations, and novel biomarkers. Bioinformatics, cheminformatics, or text analytics are three kinds of knowledge-based techniques. Knowledge-based approaches improve prediction confidence by incorporating a large quantity of data for drug repurposing. The most promising repurposing conclusion comes from a mix of biological, chemical, and diagnostic features, which can lay the groundwork for introducing a strong target for an already-approved medicine, as well as a detailed understanding of its mechanism of action.

A pharmaceutical development system uses bioinformatics mining (computational biology) to identify novel inter-relationships and perhaps new property rights in a specific study phenomenon by using data obtained privately or from publicly released sources. When a group uses its own biological data for repurposing research, it is common for them to look at different disease conditions. On the other hand, generalist groups do not focus their efforts on a single illness; instead, they create a panel of disease-relevant models 
and then screen chemicals that can be reused globally. Specialists rely on their ability and specialty within a particular disease area to test vast numbers of chemicals against a selected set of disorders.

Two key aspects must be thoroughly examined in order to know how to appropriately repurpose these safe pharmacological molecules to acceptable applications. To begin with, each given small-molecule drug candidate can potentially interact with a wide range of proteins. Second, complex disorders are typically the outcome of complicated intraand inter-cellular molecular interactions that are standardized and organized regularly. Often, information concerning drug-protein relationships is insufficient, and most of the computerized data analysis for repurposing originates through the combination of many data sources. Very notably, this occurs at the intersection of conventional clinical care, chemistry, biology, and toxicological rules.

In a drug repurposing strategy, bioinformatics-based techniques have been effective in discovering novel links among biological variables such as genes, biological processes, and illnesses. Another approach uses transcriptional data for therapeutic repurposing, which involves finding drugs with opposing transcriptional profiles that target a disease. Considering the current technique's unimpressive effectiveness, emerging transcriptionbased approaches such as $\mathrm{CuGuCtD}$ are improving our knowledge and ability to determine if a chemical has the capability to regulate gene expression genes in the very same manner as the chemicals that are currently managing that illness does [50,75].

For the need of medication, repositioning may even arise following positive phase I clinical study consequences, including the quality and system of an acceptable clinical situation for phase II or III studies in cheminformatics. The identification of relevant biomarkers confirms requests for activation assumption. A disorderly behavior might be owing to a lack of knowledge of the target protein's involvement in illness occurrence and development if the therapy is a proven hit to the targets.

\section{Techniques Based on Signatures}

Gene signatures produced from illness omics data even without therapy are used in signature-based medication repurposing techniques to find undiscovered off-targets or disease causes. Signature-based techniques use deterministic data at the molecular levels, such as a gene mutation and successive protein production, to unveil unidentified modes of action of bioactive compounds, using strategies such as normalized gene co-expression network analysis (WGCNA) to CMap, as well as the Library of Integrated Network-Based Cellular Signatures (LINCS) [74].

The benefit of these approaches is that they may be used to investigate undiscovered pharmacological modes of action. In contrast to knowledge-based mechanisms, signaturebased strategies use computational methodologies to examine pharmacological processes at a microscopic level, such as changes in gene expression. As microarray and nextgeneration sequencing techniques improve, massive amounts of genomics data relevant to medication repurposing studies gather, which might be utilized to uncover gene signatures for investigating unknown disease-altering pathways. Because individual gene signatures determine a medicine's efficacy, a gene signature database can aid drug repurposing using computational approaches.

\section{AI-Based Approaches}

$\mathrm{AI}$ is a portion of computer-aided drug design (CADD), which, alongside the emergence of AI, is inexorable, limiting the restrictions of a computational methodology in drug repositioning and drug discovery. The machine learning cognitive approach has progressed to deep learning approaches that encourage better data processing, dependable outcomes in the shortest feasible time, and significant expense.

In critical situations, such as the present COVID-19 worldwide outbreak, AI has proven to be a valuable addition to medication repositioning. For example, BenevolentAI, London, $\mathrm{UK}$, an AI predictive approach based on an extensive collection of structured medical data 
that incorporates multiple linkages retrieved from research journals using deep learning, has benefited in discovering possible COVID-19 medication repositioning options $[57,74]$. The AI sector contributes to the battle against COVID-19 by creating publicly available web servers and tools, such as the Confederation of Laboratories for Artificial Intelligence Research in Europe (CLAIRE AISBL), which comprises 381 AI-related laboratories and institutes around Europe [76].

Drug repositioning is one of the study subjects in this setting, with data and computational tools available to scientists and researchers. Recently, researchers have developed a deep learning strategy for finding commercialized medications that may have antiviral properties towards coronaviruses [76,77]. The approach was designed to swiftly evaluate many chemicals using given learning datasets to identify those with potential anti-SARSCoV-2 activity. However, publications based on AI research are insufficient for drug repurposing and the expansion of a big pool of biological and chemical data. Robust computation and systems for data mining are required to ensure a quick, high-efficiency, and low-cost drug discovery procedure. Computational methodologies combined with AI offer great potential for drug repositioning, especially in light of the COVID-19 epidemic, which desperately needs a cure. Furthermore, this method is as good as or better in certain circumstances than in vitro experiments.

\section{Drugs Repurposed against SARS CoV-2 Drug Targets}

Drug repositioning is not only a current scientific trend but spans across several decades. Drugs with a specific clinical indication have been further tested to discover alternative clinical indications for different diseases. The most common drug repurposing examples are NSAIDs (anti-inflammatory drugs) being used as anticancer agents. Chloroquine, an antimalarial drug, and azithromycin, an antibacterial antibiotic are under development as antiviral drugs against COVID-19 [50]. Drugs currently being tested for repositioning in COVID-19 can be distinguished as drugs potentially able to inhibit one or more steps of the coronavirus lifecycle and those that can counteract the effects of SARS-CoV-2 infection, such as the amplified immune response and the massive cytokine release, both of which lead to severe complications such as coagulopathy and acute respiratory distress syndrome (ARDS). The first is remdesivir, first developed in 2009 to treat hepatitis $C$, then repurposed to treat Ebola. Although ineffective in treating both diseases, later animal studies found that it effectively managed other coronaviruses such as SARS and MERS. It has proven effective in shortening recovery time from COVID-19 in some patients if administered early. However, it is to be used with only the most severely affected patients in critical care units. Another group of drugs that have previously been widely used among critically ill patients with SARS and MERS are glucocorticoids, powerful antiinflammatory drugs that inhibit the production and survival of T-cells and macrophages. Although controversial, glucocorticoids have been used to treat patients critically ill with COVID-19 [23,78]. A comprehensive list of repurposed drugs used against drug targets of SARS-CoV2 is provided in Table 1.

\subsection{Nafcillin}

Nafcillin is a semi-synthetic, narrow-spectrum antibiotic, a beta lactamase-resistant penicillin. The bactericidal action of penicillin inhibits cell wall synthesis due to the presence of the beta-lactam ring. However, certain bacteria develop resistance against the beta-lactam ring by synthesizing beta-lactam inhibitors (i.e., beta-lactamase or penicillinase). Penicillinase resistance drugs were introduced to combat this resistance [25]. Currently, nafcillin is being used to treat penicillinase-producing staphylococcal species, particularly methicillin-sensitive Staphylococcus aureus (MSSA). Nafcillin is also being used to treat non-specific lower respiratory tract infections and community-acquired pneumonia (CAP) [26]. Nafcillin is not known to cause life-threatening adverse side effects. An analysis by Das et al. shows the highest binding affinity with the TMD domain of monomeric E-protein [78]. Thus, nafcillin can be considered for redirecting its purpose for 
the treatment of SARS-CoV-2 infection as it could also combat bacterial co-infection in a COVID patient, which produces the same symptoms as seen in SARS-CoV-2 infection.

\subsection{Nabumetone}

Nabumetone is an FDA-approved non-selective anti-inflammatory drug (NSAID) that is currently being used for its anti-inflammatory and antipyretic effects. It is a prodrug that goes through biotransformation within the liver to produce the active component, 6-methoxy-2-naphthyl acetic acid (6MNA), that inhibits the synthesis of prostaglandins by acting on cyclooxygenase (COX) I and II. Prostaglandins are responsible for initiating fever by signaling the hypothalamus to increase body temperature. Prostaglandin acts as an inflammatory mediator acting on blood vessels to promote an inflammatory response. NSAIDs mediate anti-inflammatory effects by preventing vasodilation, reducing capillary permeability and cytokine release from endothelial cells. Altogether, these effects impede the migration of immunocompetent cells to the injury site, thereby preventing uncontrolled immune system activation and inflammation [26].

\subsection{Octacosanol}

Octacosanol is the main component of plant-extracted natural wax and is a lowmolecular-weight primary aliphatic alcohol. Its role is mainly investigated for the treatment of Parkinson's disease. It is approved as a nutraceutical by the FDA and is marketed as the main component of policosanol (PC), a generic term for a natural mixture of primary alcohols isolated originally from sugarcane wax.

\subsection{Cinametic Acid}

Cinametic acid is an FDA-approved food additive, mainly obtained from oil of cinnamon and other plant sources. Among the many therapeutic functions of cinnamic acid, one of its roles has also been linked to inhibiting angiotensin-converting enzyme (ACE). ACE converts angiotensin (Ang) I to Ang II. Ang II is responsible for constricting blood vessels and increasing blood pressure or hypertension, one of the risk factors for COVID-19, via binding to angiotensin1 receptor (AT1R) and activating a cascade of signaling pathways. The role of cinametic acid in inhibiting ACE will hamper conversion of Ang I to Ang II, which can reduce hypertension. Further, Ang II gets converted to Ang-(I-VII) by ACE2 in the absence of ACE.

\subsection{Ascorbyl Palmitate}

Ascorbyl palmitate is an FDA-approved small molecule. Mainly, it is a fat-soluble form of vitamin $C$ formed by the ester of ascorbic acid and palmitic acid. Being an amphipathic molecule, it has the advantage of being more stable and easily enters into cell membranes.

\subsection{Guaifenesin}

Guaifenesin is an FDA-approved over-the-counter (OTC) or non-prescription expectorant for treatment of cough and the common cold. It aids in the clearance of mucous and other respiratory tract secretion by increasing the volume of trachea and bronchi and reducing mucus viscosity, otherwise leading to congestion, chronic bronchitis, and COPD, commonly seen in ARDS. As a result of this, the action of guaifenesin results in a more productive cough, thus combating the condition of ARDS. This is also expected to happen if administered to COVID-19 patients as it can potentially disrupt the formation of the pentameric structure of E-protein, which causes ARD [78].

\subsection{Remdesivir}

Remdesivir, a nucleoside analogue prodrug, was developed for use against the Ebola virus, is currently under trial at many medical institutions, and is known to be effective against MERS-CoV. It has demonstrated a better safety profile than other drugs in treating acute Ebola viral infections. It gets activated into triphosphate, inhibits viral 
RNA polymerase, and has manifested in vitro and in vivo activity against MERS-CoV and SARS-CoV-2. It effectively treated a severe patient with severe pneumonia who needed mechanical ventilation but not inotropic agents for support of circulation. Findings have been mixed in studies being conducted regarding the efficacy of remdesivir for COVID-19 treatment. A multinational cohort study supported by Gilead Sciences showed clinical improvement for $68 \%$ of severe COVID-19 patients treated with compassionate use of remdesivir [79].

\subsection{Molnupiravir}

Molnupiravir is an isopropyl ester prodrug, which initially emerged as a possible treatment of influenza viruses, and encephalitic alphaviruses such as Venezuelan, Eastern, and Western equine encephalitic viruses. It is derived from the ribonucleoside analog $\beta$-D-N4-hydroxycytidine (NHC) triphosphate that converts to its active form molnupiravir (MTP) in the cell. This drug appears to work by the mechanism of "error catastrophe"; this is essentially the concept that by increasing the rate of mutation in the viral genome beyond a biologically tolerable threshold, the virus will no longer be able to exist. It is a broad-spectrum antiviral drug with a two-step mutagenesis mechanism. It targets the virally encoded RdRp of the SARS-CoV-2 and competitively inhibits the cytidine and uridine triphosphates and incorporates MTP. The RdRp utilizes the NHC triphosphate to incorporate either $\mathrm{A}$ or $\mathrm{G}$ in the active centers. This, in turn, helps in escaping proofreading of a mutated RNA. The resulting mutagenesis is lethal to the virus [80].

\subsection{Nirmatrelvir}

Nirmatrelvir is an irreversible inhibitor of SARS-CoV-2 drug target Mpro. It is coformulated with ritonavir, allowing an oral route of administration (known as Paxlovid). When treatment is initiated during the first days after symptom onset, it results in roughly 90\% protection against severe COVID-19 patients [81].

\subsection{Ganciclovir}

Ganciclovir, originally used to treat cytomegalovirus (CMV) infection, has shown effectiveness in a study for COVID-19 treatment at $0.25 \mathrm{~g}$ intravenously every $12 \mathrm{~h}$. Several other studies have also found such antiviral drugs to reduce viral load and avert possible respiratory impediments [82].

Table 1. A list of drugs that are being repurposed as viable treatment options against drug targets of SARS-CoV2.

\begin{tabular}{|c|c|c|c|}
\hline Targets & PDB ID & Repurposed Drugs & References \\
\hline Envelope $(\mathrm{E})$ protein & $7 \mathrm{~K} 3 \mathrm{G}$ & $\begin{array}{l}\text { Ascorbyl palmitate, cinametic acid, lauric acid, guaifenesin, } \\
\text { nabumetone, nafcillin, octacosanol, palmidrol, and salmeterol }\end{array}$ & [78] \\
\hline Main protease (Mpro). & 7C2Q & $\begin{array}{l}\text { Dipyridamole, candesartan cilexetil, candesartan, oxytetracycline, } \\
\text { valganciclovir hydrochloride, roxatidine acetate, omeprazole, } \\
\text { sulfacetamide, cimetidine, disulfiram, atazanavir, } \\
\text { hydroxychloroquine, chloroquine, indinavir montelukast sodium, } \\
\text { and maribavir }\end{array}$ & [83] \\
\hline Membrane $(\mathrm{M})$ protein & $3 \mathrm{I} 6 \mathrm{G}$ & $\begin{array}{c}\text { Colchicine, remdesivir, bafilomycin A1, temozolomide, and } \\
\text { colchicine derivatives }\end{array}$ & [84] \\
\hline Nucleocapsid $(\mathrm{N})$ protein & $6 \mathrm{M} 3 \mathrm{M}$ & $\begin{array}{l}\text { Apamycin, camostat, nafamostat, saracatinib, trametinib, } \\
\text { cefuroxime, ceftriaxone, cefotaxime }\end{array}$ & [85] \\
\hline $\begin{array}{l}\text { RNA-dependent RNA } \\
\text { polymerase (RdRp) }\end{array}$ & 7D4F & $\begin{array}{l}\text { molnupiravir, grazoprevir, ganciclovir, atazanavir, daclatasvir, } \\
\text { acyclovir, etravirine, entecavir, efavirenz, asunaprevir, abacavir } \\
\text { dolutegravir, lomibuvir, penciclovir, trifluridine, danoprevir, } \\
\text { ritonavir, saquinavir, raltegravir, and lamivudine }\end{array}$ & [86] \\
\hline S-protein & $6 \mathrm{VXX}$ & Pemirolast, isoniazid pyruvate, nitrofurantoin, and eriodictyol & [87] \\
\hline
\end{tabular}




\section{Discussion}

Drug rediscovery is cost-effective because it can increase therapeutic options and reduce drug-development-associated costs. However, there is a need for a structured protocol to repurpose previously approved drugs for other diseases to optimize licensing and avoid long-lasting procedures. Even though drug repurposing can significantly decrease the time usually required for a drug to reach the market, it is a process that is still associated with many challenges, whether from a regulatory or a scientific perspective. Close collaboration between researchers is needed to evaluate existing evidence critically and strategically plan the generation of new preclinical, clinical, and observational evidence to investigate drug efficacy and safety for potential repurposing. One of the main objectives should be to avoid duplication of studies and plan studies to compare the evaluated outcomes. Preclinical, clinical and observational research all generate complementary information, which is necessary in building the case for drug repurposing.

\section{Conclusions}

The effectiveness of drug repurposing strategies is determined by whether such agents will compare with virus-specific vaccines or small molecules. A broad-spectrum strategy may have fundamental flaws, much like antibiotics, as more virulent, drug-resistant strains emerge. Drugs like remdesivir and chloroquine have essentially suffered from fallacies against COVID-19 as preclinical assumptions overestimate their clinical efficacy. This shows that even repurposed drugs may require extensive clinical trials. However, a global health emergency of the magnitude of the COVID-19 pandemic calls for a bold medical intervention, where speed is of utmost importance. Drug repurposing cuts down a substantial amount of research time and the effective cost. Such strategies may also uncover the effectiveness of drugs that have otherwise failed to demonstrate their efficacy against the original target.

While efforts are underway to seek new indications for existing compounds, regulatory committees must take rapid action to minimize any hurdles, such as updating drug licensure guidelines through repurposing. Furthermore, it is not just a battle against COVID-19, but it is a revolution for the very concept of antiviral drugs and their clinical implications.Drug repurposing endeavours shall proffer multiple uses of a single drug for multiple diseases, thus preparing humanity for a progressive future.

Author Contributions: S.R. and A.N.J. are responsible for the conceptualization of the article. A.K., U.P., S.R. and A.N.J. have contributed towards writing, review, and editing. S.R. and A.N.J. were involved in the supervision of the complete process. All authors have read and agreed to the published version of the manuscript.

Funding: This research received no external funding.

Institutional Review Board Statement: Not applicable.

Informed Consent Statement: Not applicable.

Data Availability Statement: Not applicable.

Conflicts of Interest: The authors declare no conflict of interest.

\section{References}

1. Singh, T.U.; Parida, S.; Lingaraju, M.C.; Kesavan, M.; Kumar, D.; Singh, R.K. Drug repurposing approach to fight COVID-19. Pharmacol. Rep. 2020, 72, 1479-1508. [CrossRef] [PubMed]

2. Khan, S.A.; Al-Balushi, K. Combating COVID-19: The role of drug repurposing and medicinal plants. J. Infect. Public Health 2021, 14, 495-503. [CrossRef] [PubMed]

3. Loucera, C.; Esteban-Medina, M.; Rian, K.; Falco, M.M.; Dopazo, J.; Pena-Chilet, M. Drug repurposing for COVID-19 using machine learning and mechanistic models of signal transduction circuits related to SARS-CoV-2 infection. Signal Transduct. Target. Ther. 2020, 5, 290. [CrossRef] [PubMed] 
4. Chowdhury, K.H.; Chowdhury, M.R.; Mahmud, S.; Tareq, A.; Hanif, N.B.; Banu, N.; Ali Reza, A.S.M.; Emran, T.B.; Simal-Gandara, J. Drug Repurposing Approach against Novel Coronavirus Disease (COVID-19) through Virtual Screening Targeting SARS-CoV-2 Main Protease. Biology 2021, 10, 2. [CrossRef]

5. World Health Organization. WHO Coronavirus (COVID-19) Dashboard. Available online: https://covid19.who.int/ (accessed on 16 January 2022).

6. Ahmad, L. Implication of SARS-CoV-2 Immune Escape Spike Variants on Secondary and Vaccine Breakthrough Infections. Front. Immunol. 2021, 12, 742167. [CrossRef] [PubMed]

7. Harvey, W.T.; Carabelli, A.M.; Jackson, B.; Gupta, R.K.; Thomson, E.C.; Harrison, E.M.; Ludden, C.; Reeve, R.; Rambau, A.; Peacock, S.J.; et al. SARS-CoV-2 variants, spike mutations and immune escape. Nat. Rev. Microbiol. 2021, 19, 409-424. [CrossRef]

8. Sanyaolu, A.; Okorie, C.; Marinkovic, A.; Haider, N.; Abbasi, A.F.; Jaferi, U.; Prakash, S.; Balendra, V. The emerging SARS-CoV-2 variants of concern. Ther. Adv. Infect. Dis. 2021, 8, 20499361211024372. [CrossRef]

9. Brosnahan, S.B.; Jonkman, A.H.; Kugler, M.C.; Munger, J.; Kaufman, D.A. COVID-19 and Respiratory System Disorders. Arter. Thromb. Vasc. Biol. 2020, 40, 2586-2597. [CrossRef]

10. Mani, D.; Wadhwani, A.; Krishnamurthy, P.T. Drug Repurposing in Antiviral Research: A Current Scenario. J. Young Pharm. 2019, 11, 117-121. [CrossRef]

11. Chakraborty, C.; Sharma, A.R.; Bhattacharya, M.; Agoramoorthy, G.; Lee, S.-S. The Drug Repurposing for COVID-19 Clinical Trials Provide Very Effective Therapeutic Combinations: Lessons Learned From Major Clinical Studies. Front. Pharmacol. 2021, 12, 12. [CrossRef]

12. Yang, H.T.; Rao, Z.H. Structural biology of SARS-CoV-2 and implications for therapeutic development. Nat. Rev. Microbiol. 2021, 19, 685-700. [CrossRef] [PubMed]

13. Jang, W.D.; Jeon, S.; Kim, S.; Lee, S.Y. Drugs repurposed for COVID-19 by virtual screening of 6218 drugs and cell-based assay. Proc. Natl. Acad. Sci. USA 2021, 118, 118. [CrossRef] [PubMed]

14. Cai, Y.F.; Zhang, J.; Xiao, T.S.; Peng, H.Q.; Sterling, S.M.; Walsh, R.M.; Rawson, S.; Rits-Volloch, S.; Chen, B. Distinct conformational states of SARS-CoV-2 spike protein. Science 2020, 369, 1586-1592. [CrossRef] [PubMed]

15. Parsegian, V.A.; Fuller, N.; Rand, R.P. Measured work of deformation and repulsion of lecithin bilayers. Proc. Natl. Acad. Sci. USA 1979, 76, 2750-2754. [CrossRef] [PubMed]

16. Khan, M.I.; Khan, Z.A.; Baig, M.H.; Ahmad, I.; Farouk, A.E.; Song, Y.G.; Dong, J.-J. Comparative genome analysis of novel coronavirus (SARS-CoV-2) from different geographical locations and the effect of mutations on major target proteins: An in silico insight. PLOS ONE 2020, 15, e0238344. [CrossRef]

17. Paul, D.; Pyne, N.; Paul, S. Mutation profile of SARS-CoV-2 spike protein and identification of potential multiple epitopes within spike protein for vaccine development against SARS-CoV-2. Virusdisease 2021, 32, 703-726. [CrossRef]

18. Walls, A.C.; Park, Y.J.; Tortorici, M.A.; Wall, A.; McGuire, A.T.; Veesler, D. Structure, Function, and Antigenicity of the SARS-CoV-2 Spike Glycoprotein. Cell 2020, 183, 1735. [CrossRef]

19. Perišić, O. Recognition of Potential COVID-19 Drug Treatments through the Study of Existing Protein-Drug and Protein-Protein Structures: An Analysis of Kinetically Active Residues. Biomolecules 2020, 10, 1346. [CrossRef]

20. Leowattana, W. COVID-19: Potential Repurposing Drugs. Infect. Disord—Drug Targets 2021, 21, 1. [CrossRef]

21. Mandala, V.S.; McKay, M.J.; Shcherbakov, A.A.; Dregni, A.J.; Kolocouris, A.; Hong, M. Structure and drug binding of the SARS-CoV-2 envelope protein transmembrane domain in lipid bilayers. Nat. Struct. Mol. Biol. 2020, 27, 1202-1208. [CrossRef]

22. Nawaz, S. COVID-19, SARS-CoV-2, Origin, Transmission and Treatment Aspects, a Brief Review. Infect. Disord Drug Targets 2021, 21, e270421186673. [CrossRef]

23. Balaji Hange, V. A Narrative Literature Review of Global Pandemic Novel Coronavirus Disease 2019 (COVID-19): Epidemiology, Virology, WŽłĞn $\theta$ Ăů Drug Treatments Available. Arch. Med. 2020, 12, 1-9. [CrossRef]

24. Noor, R. A comparative review of pathogenesis and host innate immunity evasion strategies among the severe acute respiratory syndrome coronavirus 2 (SARS-CoV-2), severe acute respiratory syndrome coronavirus (SARS-CoV) and the Middle East respiratory syndrome coronavirus (MERS-CoV). Arch. Microbiol. 2021, 203, 1943-1951. [PubMed]

25. Jarada, T.N.; Rokne, J.G.; Alhajj, R. A review of computational drug repositioning: Strategies, approaches, opportunities, challenges, and directions. J. Cheminformatics 2020, 12, 46. [CrossRef] [PubMed]

26. Ng, Y.L.; Salim, C.K.; Chu, J.J.H. Drug repurposing for COVID-19: Approaches, challenges and promising candidates. Pharmacol Ther. 2021, 228, 107930. [CrossRef] [PubMed]

27. Lipinski, C. Drug repurposing. In Drug Discovery Today: Therapeutic Strategies; Elsevier: Amsterdam, The Netherlands, 2011.

28. Senanayake, S.L. Drug repurposing strategies for COVID-19. Futur. Drug Discov. 2020, 2, 2. [CrossRef]

29. Dhaneshwar, S.; Bhasin, B. Drug Repurposing: An Emerging Tool for Drug Reuse, Recycling and Discovery. Curr. Drug Res. Rev. 2021, 13, 101-119. [CrossRef]

30. Naasani, I. COMPARE Analysis, a Bioinformatic Approach to Accelerate Drug Repurposing against COVID-19 and Other Emerging Epidemics. SLAS Discov. Adv. Sci. Drug Discov. 2021, 26, 345-351. [CrossRef]

31. Talevi, A.; Bellera, C.L. Challenges and opportunities with drug repurposing: Finding strategies to find alternative uses of therapeutics. Expert Opin. Drug Discov. 2020, 15, 397-401. [CrossRef]

32. Pushpakom, S.; Iorio, F.; Eyers, P.A.; Escott, K.J.; Hopper, S.; Wells, A.; Doig, A.; Guilliams, T.; Latimer, J.; McNamee, C.; et al. Drug repurposing: Progress, challenges and recommendations. Nat. Rev. Drug Discov. 2019, 18, 41-58. [CrossRef] 
33. Molina, D.M.; Jafari, R.; Ignatushchenko, M.; Seki, T.; Larsson, E.A.; Dan, C.; Sreekumar, L.; Cao, Y.; Nordlund, P. Monitoring Drug Target Engagement in Cells and Tissues Using the Cellular Thermal Shift Assay. Science 2013, 341, 84-87. [CrossRef] [PubMed]

34. Friman, T.; Chernobrovkin, A.; Molina, D.M.; Arnold, L. CETSA MS Profiling for a Comparative Assessment of FDA-Approved Antivirals Repurposed for COVID-19 Therapy Identifies TRIP13 as a Remdesivir Off-Target. SLAS Discov. Adv. Sci. Drug Discov. 2021, 26, 336-344. [CrossRef] [PubMed]

35. Weisberg, E.; Parent, A.; Yang, P.L.; Sattler, M.; Liu, Q.; Liu, Q.; Wang, J.; Meng, C.; Buhrlage, S.J.; Gray, N.; et al. Repurposing of Kinase Inhibitors for Treatment of COVID-19. Pharm. Res. 2020, 37, 167. [CrossRef] [PubMed]

36. Chen, C.-Y.; Chen, W.-C.; Hsu, C.-K.; Chao, C.-M.; Lai, C.-C. Clinical efficacy and safety of Janus kinase inhibitors for COVID-19: A systematic review and meta-analysis of randomized controlled trials. Int. Immunopharmacol. 2021, 99, 108027. [CrossRef]

37. Xu, M.; Lee, E.M.; Wen, Z.; Cheng, Y.; Huang, W.-K.; Qian, X.; Tcw, J.; Kouznetsova, J.; Ogden, S.C.; Hammack, C.; et al. Identification of small-molecule inhibitors of Zika virus infection and induced neural cell death via a drug repurposing screen Nat. Med. 2016, 22, 1101-1107. [CrossRef]

38. Sun, W.; Weingarten, R.A.; Xu, M.; Southall, N.; Dai, S.; Shinn, P.; Sanderson, P.E.; Williamson, P.R.; Frank, K.M.; Zheng, W. Rapid antimicrobial susceptibility test for identification of new therapeutics and drug combinations against multidrug-resistant bacteria. Emerg. Microbes. Infect. 2016, 5, e116. [CrossRef]

39. Schenone, M.; Dančík, V.; Wagner, B.K.; Clemons, P.A. Target identification and mechanism of action in chemical biology and drug discovery. Nat. Chem. Biol. 2013, 9, 232-240. [CrossRef]

40. Chen, C.E.Z.; Shinn, P.; Itkin, Z.; Eastman, R.T.; Bostwick, R.; Rasmussen, L.; Huang, R.; Shen, M.; Hu, X.; Wilson, K.M.; et al. Drug Repurposing Screen for Compounds Inhibiting the Cytopathic Effect of SARS-CoV-2. Front. Pharmacol. 2021, 11, 592737. [CrossRef]

41. Noah, J.W.; Severson, W.; Noah, D.L.; Rasmussen, L.; White, E.L.; Jonsson, C.B. A cell-based luminescence assay is effective for high-throughput screening of potential influenza antivirals. Antivir. Res. 2007, 73, 50-59. [CrossRef]

42. Jugler, C.; Sun, H.Y.; Chen, Q. SARS-CoV-2 Spike Protein-Induced Interleukin 6 Signaling Is Blocked by a Plant-Produced Anti-Interleukin 6 Receptor Monoclonal Antibody. Vaccines 2021, 9, 1365. [CrossRef]

43. Dan, J.; Mehta, S. Severe Acute Respiratory Syndrome Coronavirus 2 (SARS-CoV-2) Immunity and Reinfection. Clin. Infect. Dis. 2021, 73, E2992-E2994. [CrossRef] [PubMed]

44. Samimi, N.; Farjam, M.; Klionsky, D.J.; Rezaei, N. The role of autophagy in the pathogenesis of SARS-CoV-2 infection in different cell types. Autophagy 2021, 1-4. [CrossRef] [PubMed]

45. Tayara, H.; Abdelbaky, I.; Chong, K.T. Recent omics-based computational methods for COVID-19 drug discovery and repurposing. Brief. Bioinform. 2021, 22, 22. [CrossRef] [PubMed]

46. Sharma, K.; Morla, S.; Goyal, A.; Kumar, S. Computational guided drug repurposing for targeting 2'-O-ribose methyltransferase of SARS-CoV-2. Life Sci. 2020, 259, 118169. [CrossRef]

47. Parvathaneni, V.; Kulkarni, N.S.; Muth, A.; Gupta, V. Drug repurposing: A promising tool to accelerate the drug discovery process. Drug Discov. Today 2019, 24, 2076-2085. [CrossRef]

48. Hazarika, Z.; Rajkhowa, S.; Jha, A.N. Role of Force Fields in Protein Function Prediction. In Homology Molecular ModelingPerspectives and Applications; IntechOpen: London, UK, 2021.

49. Das, A.; Pathak, U.; Rajkhowa, S.; Jha, A.N. Plasmodium falciparum: Experimental and Theoretical Approaches in Last 20 Years. In Current Topics and Emerging Issues in Malaria Elimination; IntechOpen: London, UK, 2021.

50. Rudrapal, M.; Khairnar, J.; Jadhav, G. Drug repurposing (DR): An emerging approach in drug discovery. In Drug Repurposing Hypothesis, Molecular Aspects and Therapeutic Applications; IntechOpen: London, UK, 2020.

51. Behera, S.K.; Vhora, N.; Contractor, D.; Shard, A.; Kumar, D.; Kalia, K.; Jain, A. Computational drug repurposing study elucidating simultaneous inhibition of entry and replication of novel corona virus by Grazoprevir. Sci. Rep. 2021, 11, 7307. [CrossRef]

52. Zhou, G.; Stewart, L.; Reggiano, G.; DiMaio, F. Computational Drug Repurposing Studies on SARS-CoV-2 Protein Targets. Biol. Med. Chem. 2020, 1. [CrossRef]

53. Wang, J. Fast Identification of Possible Drug Treatment of Coronavirus Disease-19 (COVID-19) through Computational Drug Repurposing Study. J. Chem. Inf. Model. 2020, 60, 3277-3286. [CrossRef]

54. Meng, X.-Y.; Zhang, H.-X.; Mezei, M.; Cui, M. Molecular Docking: A Powerful Approach for Structure-Based Drug Discovery. Curr. Comput. Aided Drug Des. 2011, 7, 146-157. [CrossRef]

55. Hazarika, Z.; Jha, A.N. A Comparative Evaluation of Docking Programs using Influenza Endonuclease as Target Protein. In Proceedings of the 2020 International Conference on Computational Performance Evaluation (ComPE), Shillong, India, 2-4 July 2020; pp. 321-326.

56. Das, S.; Khanikar, P.; Hazarika, Z.; Rohman, M.A.; Uzir, A.; Jha, A.N.; Roy, A.S. Deciphering the Interaction of 5,7-Dihydroxyflavone with Hen-Egg-White Lysozyme through Multispectroscopic and Molecular Dynamics Simulation Approaches. ChemistrySelect 2018, 3, 4911-4922. [CrossRef]

57. Bzowka, M.; Mitusinska, K.; Raczynska, A.; Samol, A.; Tuszynski, J.A.; Gora, A. Structural and Evolutionary Analysis Indicate That the SARS-CoV-2 Mpro Is a Challenging Target for Small-Molecule Inhibitor Design. Int. J. Mol. Sci. 2020, 21, 3099. [CrossRef] [PubMed]

58. Jakhmola, S.; Hazarika, Z.; Jha, A.N.; Jha, H.C. In silico analysis of antiviral phytochemicals efficacy against Epstein-Barr virus glycoprotein H. J. Biomol. Struct. Dyn. 2021, 1-14. [CrossRef] [PubMed] 
59. Rajkhowa, S.; Borah, S.M.; Jha, A.N.; Deka, R.C. Design of Plasmodium falciparum PI(4)KIII $\beta$ Inhibitor using Molecular Dynamics and Molecular Docking Methods. ChemistrySelect 2017, 2, 1783-1792. [CrossRef]

60. Tatar, G.; Ozyurt, E.; Turhan, K. Computational drug repurposing study of the RNA binding domain of SARS-CoV-2 nucleocapsid protein with antiviral agents. Biotechnol. Prog. 2021, 37, e3110. [CrossRef] [PubMed]

61. Rajkhowa, S.; Deka, R.C. Protein-Ligand Docking Methodologies and Its Application in Drug Discovery. In Oncology: Breakthroughs in Research and Practice; IGI Publishers: Hershey, PA, USA, 2017; pp. 891-914.

62. Jalalvand, A.; Khatouni, S.B.; Najafi, Z.B.; Fatahinia, F.; Ismailzadeh, N.; Farahmand, B. Computational drug repurposing study of antiviral drugs against main protease, RNA polymerase, and spike proteins of SARS-CoV-2 using molecular docking method. J. Basic Clin. Physiol. Pharmacol. 2021, 20200369. [CrossRef]

63. Anand, J.; Ghildiyal, T.; Madhwal, A.; Bhatt, R.; Verma, D.; Rai, N. Computational guided approach for drug repurposing against SARS-CoV-2. Future Virol. 2021, 16, 211-243. [CrossRef]

64. Egieyeh, S.; Egieyeh, E.; Malan, S.; Christofells, A.; Fielding, B. Computational drug repurposing strategy predicted peptide-based drugs that can potentially inhibit the interaction of SARS-CoV-2 spike protein with its target (humanACE2). PLoS ONE 2021, 16, e0245258. [CrossRef]

65. Iorio, F.; Saez-Rodriguez, J.; di Bernardo, D. Network based elucidation of drug response: From modulators to targets. BMC Syst. Biol. 2013, 7, 139. [CrossRef]

66. Fiscon, G.; Conte, F.; Farina, L.; Paci, P. SAveRUNNER: A network-based algorithm for drug repurposing and its application to COVID-19. PLoS Comput. Biol. 2021, 17, e1008686. [CrossRef]

67. Bora, N.; Jha, A.N. In silico Metabolic Pathway Analysis Identifying Target Against Leishmaniasis-A Kinetic Modeling Approach Front. Genet. 2020, 11, 179. [CrossRef]

68. Zhou, Y.D.; Hou, Y.; Shen, J.Y.; Huang, Y.; Martin, W.; Cheng, F.X. Network-based drug repurposing for novel coronavirus 2019-nCoV/SARS-CoV-2. Cell Discov. 2020, 6, 14. [CrossRef] [PubMed]

69. Rajkhowa, S.; Hazarika, Z.; Jha, A.N. Systems biology and bioinformatics approaches in leishmaniasis. In Applications of Nanobiotechnology for Neglected Tropical Diseases; Elsevier: Waltham, MA, USA, 2021; pp. 509-548.

70. Low, Z.; Farouk, I.; Lal, S. Drug Repositioning: New Approaches and Future Prospects for Life-Debilitating Diseases and the COVID-19 Pandemic Outbreak. Viruses 2020, 12, 1058. [CrossRef] [PubMed]

71. Zumla, A.; Chan, J.F.W.; Azhar, E.I.; Hui, D.S.C.; Yuen, K.-Y. Coronaviruses-Drug discovery and therapeutic options. Nat. Rev. Drug Discov. 2016, 15, 327-347. [CrossRef] [PubMed]

72. Forni, D.; Cagliani, R.; Clerici, M.; Sironi, M. Molecular Evolution of Human Coronavirus Genomes. Trends Microbiol. 2017, 25 35-48. [CrossRef]

73. Paules, C.I.; Marston, H.D.; Fauci, A.S. Coronavirus Infections-More Than Just the Common Cold. JAMA J. Am. Med. Assoc. 2020, 323, 707. [CrossRef]

74. Jin, G.; Wong, S.T. Toward better drug repositioning: Prioritizing and integrating existing methods into efficient pipelines. Drug Discov. Today 2014, 19, 637-644. [CrossRef]

75. Richardson, P.; Griffin, I.; Tucker, C.; Smith, D.; Oechsle, O.; Phelan, A.; Rawling, M.; Savory, E.; Stebbing, J. Baricitinib as potential treatment for 2019-nCoV acute respiratory disease. Lancet 2020, 395, 1906. [CrossRef]

76. Ke, Y.-Y.; Peng, T.-T.; Yeh, T.-K.; Huang, W.-Z.; Chang, S.-E.; Wu, S.-H.; Hung, H.-C.; Hsu, T.-A.; Lee, S.-J.; Song, J.-S.; et al. Artificial intelligence approach fighting COVID-19 with repurposing drugs. Biomed. J. 2020, 43, 355-362. [CrossRef]

77. Dotolo, S.; Marabotti, A.; Facchiano, A.; Tagliaferri, R. A review on drug repurposing applicable to COVID-19. Brief. Bioinform. 2021, 22, 726-741. [CrossRef]

78. Das, G.; Das, T.; Chowdhury, N.; Chatterjee, D.; Bagchi, A.; Ghosh, Z. Repurposed drugs and nutraceuticals targeting envelope protein: A possible therapeutic strategy against COVID-19. Genomics 2021, 113, 1129-1140. [CrossRef]

79. Cunningham, A.C.; Goh, H.P.; Koh, D. Treatment of COVID-19: Old tricks for new challenges. Crit. Care 2020, 24, 91. [CrossRef] [PubMed]

80. Singh, A.K.; Singh, A.; Singh, R.; Misra, A. Molnupiravir in COVID-19: A systematic review of literature. Diabetes Metab. Syndr. 2021, 15, 102329. [CrossRef] [PubMed]

81. Owen, D.R.; Allerton, C.M.N.; Anderson, A.S.; Aschenbrenner, L.; Avery, M.; Berritt, S.; Boras, B.; Cardin, R.D.; Carlo, A.; Coffman, K.J.; et al. An oral SARS-CoV-2 M(pro) inhibitor clinical candidate for the treatment of COVID-19. Science 2021, 374, 1586-1593. [CrossRef] [PubMed]

82. Lai, C.C.; Shih, T.P.; Ko, W.C.; Tang, H.J.; Hsueh, P.R. Severe acute respiratory syndrome coronavirus 2 (SARS-CoV-2) and coronavirus disease-2019 (COVID-19): The epidemic and the challenges. Int. J. Antimicrob. Agents 2020, 55, 105924. [CrossRef]

83. Li, Z.; Li, X.; Huang, Y.-Y.; Wu, Y.; Liu, R.; Zhou, L.; Lin, Y.; Wu, D.; Zhang, L.; Liu, H.; et al. Identify potent SARS-CoV-2 main protease inhibitors via accelerated free energy perturbation-based virtual screening of existing drugs. Proc. Natl. Acad. Sci. USA 2020, 117, 27381-27387. [CrossRef]

84. Peele, K.A.; Kumar, V.; Parate, S.; Srirama, K.; Lee, K.W.; Venkateswarulu, T.C. Insilico drug repurposing using FDA approved drugs against Membrane protein of SARS-CoV-2. J. Pharm. Sci. 2021, 110, 2346-2354. [CrossRef]

85. Hu, X.Q.; Zhou, Z.R.; Li, F.; Xiao, Y.; Wang, Z.Y.; Xu, J.F.; Lin, Y.; Wu, D.; Zhang, L.; Liu, H.; et al. The study of antiviral drugs targeting SARS-CoV-2 nucleocapsid and spike proteins through large-scale compound repurposing. Heliyon 2021, 117, 27381-27387. [CrossRef] 
86. Beck, B.R.; Shin, B.; Choi, Y.; Park, S.; Kang, K. Predicting commercially available antiviral drugs that may act on the novel coronavirus (SARS-CoV-2) through a drug-target interaction deep learning model. Comput. Struct. Biotechnol. J. 2020, 18, 784-790. [CrossRef]

87. Faria, S.H.; Teleschi, J.G. Computational search for drug repurposing to identify potential inhibitors against SARS-COV-2 using Molecular Docking, QTAIM and IQA methods in viral Spike protein-Human ACE2 interface. J. Mol. Struct. 2021, $1232,130076$. [CrossRef] 